American Journal of Pharmaceutical Education 2015; 79 (7) Article 107.

\title{
REVIEW
}

\section{Note-taking and Handouts in The Digital Age}

\author{
Elizabeth Moore Stacy, PharmD, Jeff Cain, EdD, MS \\ University of Kentucky College of Pharmacy, Lexington, Kentucky \\ Submitted November 05, 2014; accepted February 04, 2015; published September 25, 2015.
}

Most educators consider note-taking a critical component of formal classroom learning. Advancements in technology such as tablet computers, mobile applications, and recorded lectures are altering classroom dynamics and affecting the way students compose and review class notes. These tools may improve a student's ability to take notes, but they also may hinder learning. In an era of dynamic technology developments, it is important for educators to routinely examine and evaluate influences on formal and informal learning environments. This paper discusses key background literature on student note-taking, identifies recent trends and potential implications of mobile technologies on classroom note-taking and student learning, and discusses future directions for note-taking in the context of digitally enabled lifelong learning.

Keywords: handouts, mobile-computing, note-taking, education

\section{INTRODUCTION}

Note-taking is an important aspect of formal classroom learning, ${ }^{1}$ and students who take more course lecture notes in general are higher achievers. ${ }^{2,3}$ However, a number of confounding variables affect student note-taking and, hence, student learning. These include instructional variables such as lecture structure, knowledge of forthcoming tests, perceived relevance of the lecture, and existence of and/or types of handouts provided. ${ }^{4-6}$ Because of these variables, research is mixed with regard to the best types of note-taking and whether the "process" of taking notes is actually the critical factor. ${ }^{3,5-7}$ Note-taking is a personalized task, and when individual differences with regard to note-taking ability also are considered, interpretation of the literature becomes even more complex. ${ }^{8-10}$

In addition to these historically studied variables, emerging factors also affect student note-taking. The introduction of tablet computers, note-taking applications (apps), and other education technology in the classroom are altering the way students take notes and consume and process information during class. These technological advances add to the perplexity of how to best guide faculty members and students about note-taking.

In this paper, we briefly discuss key background literature on student note-taking, introduce recent trends and potential implications of mobile technologies on

Corresponding Author: Jeff Cain, EdD, MS, 114 M Bio

Pharmaceutical Complex, University of Kentucky College of Pharmacy, 789 South Limestone St., Lexington, KY 40536.

Tel: 859-257-4429. Fax: 859-257-7297. E-mail:

jjcain00@email.uky.edu classroom note-taking and student learning, and offer alternative perspectives on handouts and note-taking.

\section{NOTE-TAKING VARIABLES}

The study of student note-taking spans years, covering a range of variables and perspectives. The ultimate goal of research on note-taking is to provide insight into what best aids and predicts student learning. Unfortunately, variables involved with note-taking and student learning prevents strong conclusions. In this section, we present primary variables pertaining to student notetaking, with an emphasis on factors relevant to today's contemporary digital environments.

\section{Presentation Styles}

Considerable debate exists regarding which types of lecture presentation styles are best for student learning. While PowerPoint is one of the easiest, most ubiquitous presentation applications, not all academics agree it is best for classroom communication. ${ }^{11}$ Some faculty members still prefer the "chalk-and-talk" method or today's contemporary version (eg, document cameras and smart boards), in which important information is written in front of the classroom and ideas are expanded on verbally. This lecture format is touted as improving communication and encouraging good note-taking skills. ${ }^{12}$ Each teaching platform has its own positives and negatives, with student format preference differing . ${ }^{12-14}$ Each format alters how students take notes, and affects the speed and pace of doing so. Regardless of the format, students perceive handouts to follow in class and to use as a reference as beneficial. ${ }^{14}$ 


\section{American Journal of Pharmaceutical Education 2015; 79 (7) Article 107.}

\section{Handout Styles}

Handouts are useful aids for student note-taking and learning. ${ }^{15}$ Thus, a key question educators struggle with is not whether to provide handouts, but how much information they should contain and in what format they should be. Some of the debate revolves around whether students learn better by transcribing lectures in their own words or by having instructor-prepared handouts so they can concentrate more on what is actually being said.

Concerns pertaining to instructor-provided notes as handouts primarily focus on issues of decreased student attendance and a reliance on external aids for learning. A student's ability to translate classroom information and reproduce it in personally meaningful written notes is a critical part of the learning process. ${ }^{16}$ Kiewra et al showed that students who recorded information during class performed better on examinations and had improved retention of information compared to those who did not. ${ }^{17}$

When assessing different teaching modalities with pharmacy students learning cardio-pulmonary resuscitation (CPR), Khan at al found that students who performed best on a post-lecture quiz were those who were told they would not be given handouts and as a result, took their own notes (they were then presented with PowerPoint lecture notes after the lecture). The authors concluded the process of taking notes contributed to the learning process, helping those specific students perform better than their peers. ${ }^{18}$ These studies mirror others in which the active process of taking notes appears to aid student learning. ${ }^{12,17,19}$

The opposing viewpoint to providing limited handouts is that lecture note-taking is cognitively demanding and students may have difficulty recording all vital information points and/or may record them inaccurately. This may be a reflection of student note-taking ability and/or instructor presentation of material, such as inaudible or fast-paced speech. The issue is one of cognitive load, ${ }^{20}$ in which student working memory may be insufficient at effectively listening to the lecture, processing the information, and then encoding it into a notes format, particularly if the pace is too fast or the material is too complex. ${ }^{9}$

For instructional decisions regarding handouts, instructors must balance the value of students transcribing their own notes with the inherent limitations of cognitive load. One strategy is to provide students with only an outline of the lecture material as opposed to the entire set of instructor slides and/or notes. In this format, students are provided cognitive scaffolding from which they can engage in the process of listening and distill only the details. Moreover, students provided with outlines of notes outperform students taking notes on their own. ${ }^{15,16}$

\section{Prescribed Note-taking Methods}

Although slightly beyond the scope of this paper, in addition to the effect of instructor presentation and handout styles on note-taking, there is a body of research regarding specific standardized student notetaking strategies. While more popular decades ago when lectures were the dominant form of content delivery, when instructor handouts were less prevalent, and when information memorization was emphasized, a number of notetaking methods have been developed in order to guide students toward the most effective ways of recording lecture material. These methods provide specific instructions on how to record lecture notes and include the Formal Outline Procedure, the Cornell Method, the Bartush Active Method, and the Verbatim Split Method. ${ }^{21,22}$

Training students in systematic note-taking approaches can be helpful to students in encoding and studying large amounts of learning content. Despite their success, these methods are largely ignored as perspectives regarding content delivery are shifting and classroom dynamics changing. Little research has been conducted on these methods in recent years, but may once again have potential merit in the context of flipped classroom formats, in which students may need to take notes on out-of-class recorded lectures in preparation for active-learning-based, in-class activities. ${ }^{23}$

\section{DIGITAL NOTE-TAKING}

The introduction of mobile computing devices in classrooms ushered in a new set of note-taking issues. Speed, legibility, and searchability are 3 positive attributes of digital note-taking. ${ }^{8}$ Because of these advantages, some students may prefer digital note-taking vs traditional handwritten notes. However, changes wrought from these advances in technology are not all positive.

Possibly the biggest concern with student use of laptops in class is computer-aided distraction. ${ }^{24}$ The lure of multi-tasking on those devices can significantly hinder student comprehension of classroom lectures. Other concerns arise in the efficacy of typed notes. Muller and Oppenheimer concluded that students who took notes on a laptop did not remember conceptual material as well as those who took handwritten notes, though they performed equally well when questioned about factual information. ${ }^{25}$ One hypothesis for this difference is the inclination for those who type their notes on a laptop to include longer notes and to take down information verbatim rather than through rephrasing. Other studies support these findings; Piolat et al showed students taking handwritten notes demonstrated better performance than students who typed digital notes on both factual and conceptual questions. ${ }^{20}$ As a result, Fink reported banning 


\section{American Journal of Pharmaceutical Education 2015; 79 (7) Article 107.}

all forms of digital note-taking, citing that, without the digital devices, students remained attentive and performed well in the course. ${ }^{26}$

\section{Introduction of Tablet Computers}

Tablet computers have further hastened the transition toward digital note-taking. One benefit of tablets for note-taking is the ability to hand write notes, add drawings, and highlight text while still retaining the digital format. Given the complex and diagram-driven content of courses in the pharmacy curriculum, a digital format that allows typing and drawing can be advantageous. In addition, tablet computers may reduce or eliminate the cost of printing, reduce the amount of paper one has to carry, decrease the need to transport a heavier and more cumbersome laptop, and support the organization of notes. $^{27}$

Although little research exists on student use of tablets for learning, Mang and Wardley indicated that students using tablets are much less likely to access distractions such as e-mail, Facebook, messengers, or YouTube during class compared to those using a laptop. ${ }^{27}$ Tablet computers are also appealing from an institutional perspective because they provide a relatively inexpensive way to incorporate digital-based learning. Several universities, most notably Notre Dame, Pepperdine, and Stanford, have started programmatic efforts designed specifically to encourage iPad use in classrooms. ${ }^{28}$

\section{Note-taking applications}

Coinciding with the introduction of tablets and smartphones was the development of mobile applications (apps), which provide easy access to a variety of functions. Literature concerning the use of mobile or tablet application in the classroom is sparse. Most information available comes from technology-centered magazines or online app reviews. The mobile app market changes rapidly, and Internet searches for note-taking/study apps reveal considerable options in functionality and price.

Informal discussions with students revealed that personal choices for app use and/or selection depend largely on classmate recommendations. Recommendations of mobile apps to aid in student success have also been presented at pharmacy student forums. Recommendations, based on student utility and reviews, included StudyBlue Flashcards (a flashcard application for studying), Evernote Peek (a note-taking and flashcard style app), Dropbox (an application used for document storage and collaboration) and note-taking applications Evernote, Notability, and Penultimate. ${ }^{29}$

Based on research regarding cognitive functions of note-taking, a variety of factors make note-taking apps appealing. In order for learning apps to be effective, they must accommodate an active note-taking process and enable efficient review of those notes. ${ }^{30}$ An application that simply allows students to copy and paste prewritten notes without including their own definitions or elaborations is much less effective than one that encourages personally written language. While verbatim notes may be more accurate, the benefit of "process" is absent, and therefore, lessens the effects of the learning experience. Apps that permit students to draw upon, edit, summarize, and highlight handouts in a manner that allows cognitive involvement in the note-taking process are most beneficial to learning. ${ }^{30}$

Formal use of apps for note-taking and learning is in its infancy. One example of an app-based initiative comes from Abilene Christian Academy, which issues each of its students an iPod Touch or iPhone to use during their education. ${ }^{31}$ The primary focus of using these devices are the apps available to enhance student learning. Chemistry professors find apps particularly useful, as they allow students to visualize complex molecules and identify chemicals and their names. ${ }^{31}$ In addition to an enhanced visual and tactile learning process, apps also can improve note-taking by allowing more complex images and other media to be integrated into students' written guides. Use of these devices in the classroom helps train students to use a variety of applications and tools crucial for careers in the digital age. Moreover, tablet and smartphone apps are now common in the clinical environment, ${ }^{32}$ with some large medical centers advocating the use of apps and supplying facility-owned iPads so its staff can securely view electronic health records. ${ }^{33}$ Studies of medical providers show that up to $85 \%$ of its study population (surgeons, fellows, and residents) own and use a smartphone in practice; more than half of those studied use applications in their daily practice. ${ }^{34}$ Use of such apps has vastly improved the ability for health care providers to access credible information, view patient charts, and complete all functions in a timely manner. ${ }^{32}$ Some apps have been evaluated and recommended for use in practice; the scope of these apps range from providing information about medications (eg, PEPID, Lexicomp, Epocrates), to time management and productivity (eg, Wunderlist, Dropbox, GoodReader). ${ }^{35}$

\section{DISCUSSION}

Most faculty members establish their own philosophies regarding handouts and note-taking. However, it may be time to consider new student-centered approaches that provide learners with the best and most efficient way of learning while in the classroom and after they graduate. Delivery style and methods can affect how students 


\section{American Journal of Pharmaceutical Education 2015; 79 (7) Article 107.}

receive, process, and record notes. Our use of technology in the classroom (ie, PowerPoint slides) may be below its potential, and faculty members may want to consider uses of instructional technology beyond efficient content delivery.

Observations of students in classrooms reveal varyious note-taking strategies, some of which involve students serving their own learning needs by modifying what faculty members give them. There is much to learn about student note-taking behaviors. The caveat is that instructors should not rely solely on learner preferences pertaining to handouts and/or note-taking to guide decisionmaking. Considerable research in the area of metacognition revealed that some individuals are unable to accurately assess their own level of comprehension or skill guiding their preferences. While these individuals may perceive a certain style or method as best for them, in reality those may be false perceptions because of an incorrect assessment of their own abilities. ${ }^{36}$

As educators continue to migrate away from traditional content-delivery modalities in classrooms toward more student-centered approaches of using face-to-face time for in-depth thinking, engaging, and applying information, classroom note-taking may change. Student accountability for managing their own learning processes may increase, thereby altering student approaches to studying. Lecture transcription may become less of an issue as instructors utilize technology to create offline lessons, recorded lectures, e-learning materials, etc.

Because digital learning materials are available at will, the need to further document them will be reduced. Some students may choose to forego notes altogether, perceiving that e-learning materials replace any need for taking notes. However, those students may need instruction regarding the cognitive benefits of note-taking, which extend beyond mere access to information for study purposes. Other students may continue recording notes as they always have, believing (correctly or incorrectly) that approach benefits them. Still others may adopt different technology-enabled methods. In courses utilizing a flipped classroom approach or in ones that emphasize active learning, it is likely that students will discover new apps and platforms that accommodate their needs before faculty members do. Educators, however, have a leadership role in shaping student practices that lead to their development as a professional. The difficult question is, thus, how educators can guide students regarding note-taking.

Existing research on student note-taking does provide a foundation, but this is an age in which some aspects of the former paradigm no longer apply. Student notetaking is evolving because a myriad of technological advances are triggering an information explosion, changing how information is managed and, to some degree, changing teaching practices. Therefore, the evolution toward a new, evidence-based comprehension of student note-taking in digital and mobile environments is important. Without an understanding of these tools and the socio-cognitive processes associated with them, we risk underutilizing powerful tools and/or making recommendations that students may not follow. One consideration is whether there are specific digital tools that aid student note-taking and learning and, if so, how instructors can best accommodate those tools. In a rapidly changing, mobile-technology environment, this question requires constant vigilance.

Another consideration is how an approach to handouts affects student note-taking, attention and, ultimately, learning retention. This instructional consideration often is unintentionally ignored. Anecdotally, some instructors comment that students do not pay attention in class and resort to memorizing copies of the PowerPoint slides. Conversely, if instructors do not provide handouts, students then complain about the lack of handouts and spend the entire class transcribing everything. In each of these cases, instructor decisions may strongly influence respective student actions. Variables such as teaching methods, assessment methods, instructor persona, and student culture contribute to these student behaviors, but a broad-based discussion of these is beyond the scope of this paper.

If handouts are the lone variable, however, one consideration consistent with research is to furnish "skeletal" notes/outlines. This type of handout provides students with a cognitive scaffolding, alleviating the need to transcribe everything, yet still forcing them to pay attention and engage in the process of note-taking. An additional consideration, referring back to our need for research on digital note-taking tools, is to provide notes in a format conducive to student manipulation on digital devices.

The handout format types most likely used by faculty members (eg, PowerPoint slides, Microsoft Word documents, and pdf formats) all have different advantages and limitations, which may indirectly contribute to different note-taking styles and methods. The style, breadth, depth, and visual layout of student notes may vary depending on whether students use paper, laptops, or tablets. This is one of the reasons new research is essential, particularly in light of recent findings regarding cognitive differences between typing and handwriting. ${ }^{25}$

Finally, as digital environments increasingly affect higher education, we should consider the evolving interplay between note-taking, information management, and 


\section{American Journal of Pharmaceutical Education 2015; 79 (7) Article 107.}

lifelong learning. The first decades of the digital age has introduced society to a variety of paradigm shifts including how we view the concepts of information storage and retrieval. Educators may need to rethink what it means to take notes and how those notes carry forward into future careers.

In a paper-based society, it was challenging, but not impossible, for students to carry all their notes with them. In addition, this made it potentially more challenging to sort through notes to review a particular concept. Now, not only can learning materials be stored on a phone or tablet, but students can find a phrase or concept in seconds. Cognitive and conceptual links can be made within and across courses. Admittedly, this is a drastic shift in thinking, but new ways of teaching (eg, flipped classrooms), new focal points for learning (eg, personal lifelong learning), and new ways of storing and accessing information (eg, mobile computing devices and apps) provide a foundation from which we can explore different models for note-taking and handouts.

\section{CONCLUSION}

Although handouts and notes are a seemingly minor point in the teaching process, we must still take an evidencebased approach to guide teaching and learning practices in this regard. While neither faculty members nor students appear to prefer one format over another, the best handouts allow ample space for students to reformat information into their own words and may even be somewhat "sparse" to encourage active listening and note-taking. Yet, the purpose of and types of note-taking may be evolving. Note-taking should not become an art lost to the ages of recorded class lectures and pre-filled handouts. Without the valuable skills of listening and recording, students might fail to become "competent practitioners (who are able to) listen, read, organize, integrate, and utilize information in the care of their patients." ${ }^{37}$ Students should use the note-taking medium that best engages their willingness and ability to learn. ${ }^{38}$ Learners must discover the delicate balance of practical use, ease, and efficacy for their note-taking strategies. In this technology-literate society and rapidly-changing learning environments, faculty members need to guide students toward managing their current and future learning needs. Research regarding learning outcomes with today's digital note-taking tools is needed, particularly as the possible existence of a physio-cognitive connection between writing and learning is considered. This research could help provide evidence-based recommendations to students and instructors regarding which formats and techniques work best for learning.

\section{REFERENCES}

1. Williams RL, Eggert AC. Note-taking in college classes: Student patterns and instructional strategies. J Gen Educ. 2002;51(3): 73-199. 2. Kiewra KA. A review of note-taking: The encoding storage paradigm and beyond. Educ Psychol Rev. 1989;2(1):147-172.

3. Kiewra KA. Providing the instructor's notes: An effective addition to student note-taking. Educ Psychol. 1985;20:33-39.

4. Harley J, Marshall S. On notes and note-taking. High Educ Q. 1974;23(2):225-235.

5. Katayama AD, Robinson DH. Getting students "partially" involved in note-taking using graphic organizers. $J$ Exp Educ, 2000;68(2):119-133.

6. Carrier CA, Williams MD, Dalgaard BR. College students' perceptions of note-taking and their relationship to selected learner characteristics and course achievement. Res High Educ. 1988; 28(3):223-239.

7. Bretzing BH, Kulhavy RW. Note-taking and depth of processing. Contemp Educ Psychol. 1979;4:145-153.

8. Kim K, Turner SA, Perez-Quinones MA. Requirements for electronic note-taking systems: A field study of note-taking in university classrooms. Educ Inf Technol. 2009;12:255-283.

9. Bui DC, Myerson J. The role of working memory abilities in lecture note-taking. Learn Individ Differ. 2014;33:12-22.

10. Peverly ST, Garner JK, Vekaria PC. Both handwriting and speed and selective attention are important to lecture note-taking. Read Writ. 2014;27:1-30.

11. Kosslyn SM, Kievit RA, Russell AG, Shephard JM. PowerPoint presentation flaws and failures: A psychological analysis. Front Psychol. 2012;3:230.

12. Seth V, Upadhyaya P, Ahmad M, Moghe V. PowerPoint or chalk and talk: Perceptions of medical students versus dental students in a medical college in India. Adv Med Educ Pract. 2010;1:11-16.

13. Shallcross DE, Harrison TG. Lectures: electronic presentations versus chalk and talk - a chemist's view. Chem Educ Res Pract. 2006;8(1):73.

14. Islam MN, Majumder MA, Ja'afar R, Rahman S. Students' perceptions of "technology-based" lecture handouts. Malays J Med Sci. 2005;12(1):26-8.

15. Avval FZ, Jarahi L, Ghazvini K, Youssefi M. Distribution of handouts in an undergraduate class to create more effective educational environment. Int J Ed Res. 2013;12(1):1-6.

16. DeZure D, Kaplan M, Deerman M. Research on student notetaking and implications for faculty and graduate student instructors. CRLT Occasional Papers. 2001;No 16. http://www.crlt.umich.edu/sites/ default/files/resource_files/CRLT_no16.pdf. Accessed August 18, 2014. 17. Kiewra KA, DuBois N, Christian D, McShane A, Meyerhoffer M, Roskelley D. Note-taking functions and techniques. J Educ Psychol. 1991;83(2):240-245.

18. Khan TM, Hassali MA, Rasool ST. A study assessing the impact of different teaching modalities for pharmacy students in a cardiopulmonary resuscitation (CPR) course. Saudi Pharm J. 2013;21(4):375-8.

19. Prince, M. Does active learning work? A review of the research. J Engr Educ. 2004;93(3):223-231.

20. Piolat A, Olive T, Kellogg RT. Cognitive effort during notetaking. Appl Cognit Psychol. 2005;19:291-312.

21. Palmatier RA. Comparison of Four Note-Taking Procedures. $J$ Reading. 1971;14(4):235-58.

22. Stahl NA, King JR, \& Henk WA. Enhancing students' notetaking through training and evaluation. J Read. 1991; 34(8): 614-622. 


\section{American Journal of Pharmaceutical Education 2015; 79 (7) Article 107.}

23. Sharma N. Lau CS. Doherty I., et al. How we flipped the medical classroom. Med Teach. 2014;1-4.

24. Cain J, Bird ER, Jones, MK. Mobile computing initiatives within pharmacy education. Am J Pharm Educ. 2008;72(4):Article 76. 25. Mueller PA, Oppenheimer DM. The pen is mightier than the keyboard: Advantages of longhand over laptop note-taking. Psychol Sci. 2014;25(6):1159-1168.

26. Fink JL. Why we banned use of laptops and "scribe notes" in our classroom. Am J Pharm Educ. 2010;74(6):article114.

27. Mang CF, Wardley LJ. Effective adoption of tablets in postsecondary education: Recommendations based on a trial of iPads in university classes. J Inf Technol Educ: Innov Pract. 2012;11:301-317. 28. Diemer TT, Fernandez E, Streepey JW. Student perceptions of classroom engagement and learning using iPads. J Teach Learn Technol. 2012;1(2):13-25.

29. Moore B, Keenan N. Student success strategies and study skills. University of Kentucky College of Pharmacy. Lexington, KY. Sept 8, 2014. Student Convocation Presentation.

30. Bauer A, Koedinger K. Pasting and encoding: Note-taking in online courses. Presented at: Sixth International Conference on Advanced Learning Technologies, 2006; July 5-7, 2006; Kerkrade, Netherlands. http://ieeexplore.ieee.org/xpl/articleDetails.jsp? arnumber $=1652559$. Accessed August 18, 2014.
31. Williams JA, Pence HE. Smartphones, a powerful tool in the chemistry classroom. J Chem Educ. 2011;88:683-686.

32. Ventola CL. Mobile devices and apps for health-care professionals: Uses and benefits. Pharm Ther. 2014;39(5): 356-64.

33. O’Neill K, Holmer H, Greenberg SLM, Meara JG. Applying surgical apps: Smartphone and tablet apps prove useful in clinical practice. Bulletin of the American College of Surgeons. http:// bulletin.facs.org/2013/11/applying-surgical-apps/. Published November 1, 2013. Accessed August 18, 2014.

34. Franko OI, Tirrell TF. Smartphone app use among medical providers in ACGME training programs. J Med Systems. 2012;36 (5):3135-3139

35. Aungst TD. Medical applications for pharmacists using mobile devices. Ann Pharmacother. 2013;47 (7-8):1088-95.

36. Bjork, RA. (1994). Memory and metamemory considerations in the training of human beings. In: Metcalfe J, Shimamura A, eds. Metacognition: Knowing About Knowing. Cambridge, MA: MIT Press; 1994: 185-205.

37. Brazeau GA. Handouts in the classroom: Is note-taking a lost skill? Am J Pharm Educ. 2006;70(2):Article 38.

38. Dror IE. Technology-enhanced learning: The good, the bad, and the ugly. Pragmatics Cognit. 2008;16:215-223. 